\title{
Synthesis of natural products based on photochemical key transformations
}

\author{
Martin Demuth \\ Max-Planck-Institut für Strahlenchemie D-4330 Mülheim a. d. Ruhr, FRG.
}

\begin{abstract}
Three photochemical methods aiming primarily at syntheses of cyclopentanoid natural products are described: (A) The development and synthetic applications of four generations of tricyclooctanone-type key intermediates - all products of oxadi- $\pi$-methane rearrangements - are reviewed. Most recent achievements are the total syntheses of (-)-5-oxosilphiperfol-6-ene and of $(-)$-coriolin.

(B) The [2+2] photocycloaddition of 2-trimethylsiloxybutadiene to a number of standard enones proved to be quite a general reaction with appreciable yields. This finding is surprising since dienes in general are known to quench enone triplets efficiently and hence suppress chemical reactions. Both the high substrate concentrations, which can be employed in the present procedure, and the remarkable regio- and stereocontrol of the addition processes qualify this annulation as a valuable synthetic method. One photoproduct is the point of departure for an expedient assembly of the basic pentalenolactone skeleton.

(C) Spirocyclic chiral 1,3-dioxenones, prepared in a one-step procedure, served for highly selective asymmetric [2+2] de Mayo-type photocycloadditions with various olefins. The value of this novel method is documented by an exploratory preparative example, a short synthesis of $(+)$-grandisol.
\end{abstract}

\section{INTRODUCTION}

The seàrch for efficient methods to construct five-membered rings (refs. 1-3) with the ultimate aim of assembling polycondensed cyclopentanoids (ref. 2) was a major concern in synthesis during the past decade. Among the methods developed, photochemical transformations play an important role. They have proved successful in providing ways to economically build up arrays of asymmetric centres. The following three parts, each based on a distinct type of photochemical transformation, illustrate our approaches in this field. Whereas the methods in sections $A$ and $B$ are - at least in the actual presentation - designed specially for the synthesis of cyclopentanoids, the method in section $C$ has the potential of intriguing applications beyond this purpose.

\section{A. REARRANGEMENTS: FOUR GENERATIONS OF OXADI- $\pi$-METHANE(ODPM)- DERIVED KEY INTERMEDIATES}

A preparatively attractive avenue to a remarkable number of structural variants of cyclopentanoid natural products is offered by the concept which uses tricyclooctanone (TCO) derivatives, products of ODPM rearrangements, as the key intermediates (building blocks) (refs. 4-7). Several advantages are connected with this principle: (a) Full optical activity - an important objective of natural products synthesis - can, in most cases, be readily introduced. (b) Reliable predictions of the course of the photochemical steps can now be made based on our experience with ODPM transformations (for a number of examples, see figs. 1 and 2 in ref. 7). (c) The flexibility of the concept is enhanced by a number of more target-oriented ODPM variants. (d) Only a few structural restrictions need be considered in designing the photochemical substrates. (e) The photochemical steps meet the conditions for large scale preparations.

Four basic types (generations) of building blocks (see Fig. 1) have been developed, a parent type (I) with a minimal set of functionalities and three more target-oriented generations (II - IV). Since most of this work has been published, a brief resumé of the synthetic accomplishments should suffice to stimulate further use of the TCO principle. 


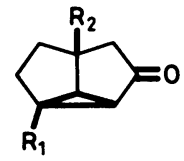

( I )

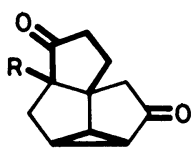

( I I )<smiles>[R]C1([R])C2CC1C1C(=O)C([R])([R])C([R])([R])C(=O)C12</smiles>

( II I )<smiles>[R]C12CCC(=O)C1CC(=O)C2</smiles>

(IV)

Fig. 1. Four generations of ODPM-derived tricyclooctanone-type building blocks. The bold lines emphasize the functionality pattern characteristic of each representative.

Syntheses of four members of the monoterpene iridoid family were completed in short sequences $v i$ a the TCO intermediate 1 (ref. 4): boschnialactone (2), allodolicholactone (3), iridomyrmecin (4), and isoiridomyrmecin (5). This route compares favourably with the most efficient of the earlier approaches published.

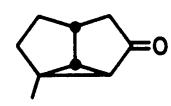

$( \pm)-1$<smiles>[R2]C1([R2])CC[C@H]2[C@@H]1COC(=O)C2([R6])[R6]</smiles>

\author{
all racemic: \\ $2 \mathrm{R}_{1}=\mathrm{CH}_{3} ; \mathrm{R}_{2}-\mathrm{R}_{4}=\mathrm{H}$ \\ $3 \quad R_{1}=H_{j} R_{2}=C_{3} ; R_{3}, R_{4}=C_{2}$ \\ $4 R_{1}, R_{4}=H_{3}, R_{2}, R_{3}=C_{3}$ \\ $5 R_{1}, R_{3}=H_{;} R_{2}, R_{4}=C_{3}$
}

TCO 6 is readily available in multigram amounts and in enantiomeric purities of $>98 \%$ ee ( $v i$ a resolution of the substrate for the photorearrangement, $i . e$. bicyclo[2.2.2] oct-5-en-2-one). From (-)-6 the first stereocontrolled preparation of natural $(+)-7$ (iridodial) was achieved in a mere six steps (ref. 8 ). Whereas oxidative ring $B$ cleavage of (-)-6 was effected here, oxidative ring An enlargement of the TCO unit was exemplified in a total synthesis of loganin aglucon 6-acetate $[(+)-8]$ (ref. 9). The latter sequence is distinguished by a higher overall yield than previous efforts in this field. A further intriguing application of $(-)-6$, for which the initial steps have been explored (ref. 4), concerns 6a-carbaprostacyclin, a prostacyclin analogue of distinct pharmacological importance.<smiles>CC(C)C1CCCC1C=O</smiles>

$(+)-7$
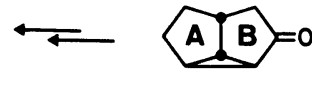

$(-1-6$

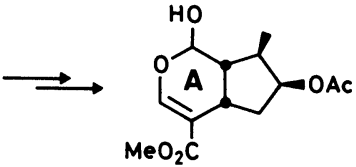

$(+1-8$

The (+)-enantiomer of 6 was tested in view of its utility for the construction of linearly fused cis, anti,cis-tricycloundecane skeletons. Such a carbacyclic framework, e.g. 9* (starred compounds denote exploratory preparations with racemic material), was established in seven steps (ref. 10). The original project, aimed at a synthesis of coriolin, was abandoned at this stage in favour of a more advantageous recent development $[$ see $(-)-17 / 18 \rightarrow(-)-19]$. Employment of $(+)-6$ for the assembly of steroidal skeletons proved highly

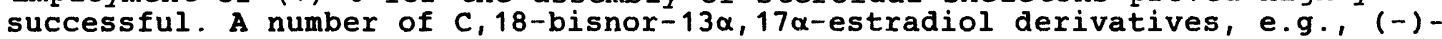
10 as one representative, could be synthesized by merely two transformations from (+)-6 (ref. 11). 10 proved to be a suitable intermediate for ring $C$ enlargement in three steps $(\rightarrow 11 *, R=C l, O H)$ (ref. 12) en route to the final introduction of the methyl $\mathrm{C}-18$, which is expected to proceed from the stereochemically correct $\beta$-face.

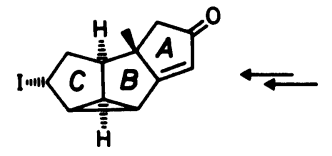

9*

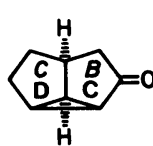

$(+)-6$

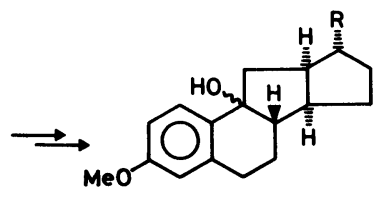

$(-)-10$

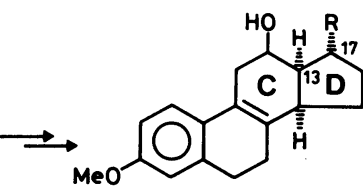

$11^{*}$

In an extension of the parent concept [generation (I) in Fig. 1], key intermediates with additional rings [generation (II)] were probed (ref. 13). In a conceptually different approach to photochemical precursor(s) readily available starting materials in optically pure form, such as $(-)-12$, were employed. On this basis, the first total synthesis of natural 5-oxosilphiperfol-6-ene [(-)-15], an angularly fused triquinane structure, has been achieved 
(ref. 14) (for the preparation of 15 in enantiomerically enriched form, see ref. 15, and for racemic syntheses, see ref. 16). The acetone-sensitized ODPM rearrangement at $\lambda(i \mathrm{r})=300 \mathrm{~nm}$ of $(t)-13$ ( $R=$ MEM group) cleanly afforded (-)-14 (70\% yield of purified product), an intermediate whose structural features were perfectly arranged for an economic completion of the scheme to $(-)-15$. Such a smooth rearrangement of $(+)-13$ was a priori not possible to predict in view of some $\beta, \gamma$-enones bearing bridgehead substituents known to be photochemically unreactive (refs. 4,6 ).

It should be noted that the approach realized in this particular triquinane synthesis may well be generally applicable for the construction of angularly fused skeletons.

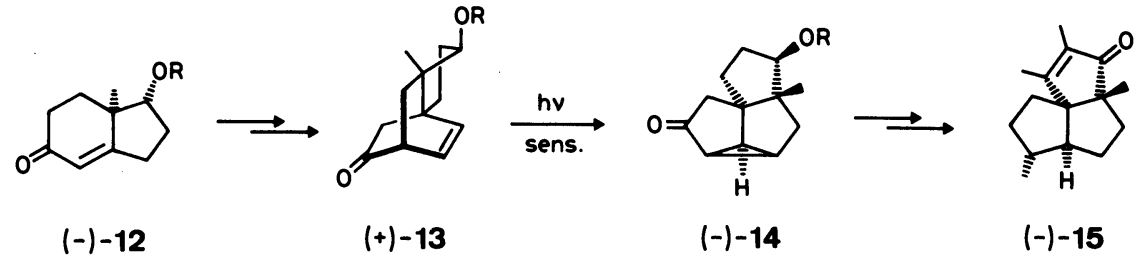

The triplet-sensitized preparation of a mixture of enantiomerically pure (-)$18 / 19$ [generation (III) intermediates] in $\geq 70 \%$ yield from ( $-1-16 / 17$ paved the way for the first total synthesis of natural coriolin $[(-)-20$, a very potent antitumor agent] in a sequence which compares favourably with the shortest racemic syntheses achieved earlier (ref. 17). Both epimeric photoproducts were equally suitable for the $A+B C \rightarrow A B C$ building-up principle chosen. The key step is characterized by a novel aspect of ODPM photochemistry, steric control by methyl substituents leading to a site selective rearrangement of one $\beta, \gamma$-enone partial chromophore of the $\beta, \gamma$-unsaturated $\varepsilon$-diketones $(-)-16 / 17,(-)-16$ was found to react at twice the conversion rate than does $(-)-17$. The 6,7 -bonding process in $(-)-16 / 17$, the prerequisite for an ODPM rearrangement to $(-)-18 / 19$, is impeded by the syn-oriented secondary methyl in $(-)-17$, a steric constraint which is not encountered in $(-)-16$ possessing an anti $c-5$ methyl. Concurrent with the ODPM process(es) and favouring the most efficient ODPM route, a second and fast photoreaction results in a 5:1 equilibration of the epimers 16 and 17. Although the mechanism of this process has not yet been fully identified, it has at least been ascertained that Norrish type I cleavage and reclosure is not a major contributor to the stereoequilibration. The preparatively attractive high substrate concentrations employed for $(-)-16 / 17 \rightarrow(-)-18 / 19$ (typical runs with $\geq 20 \%$ sample solutions in acetone, $\lambda(i \mathrm{rr})=300 \mathrm{~nm}$ ) deserve special mention since they do not affect the product yield. Competing reactions such as regioisomeric $c-3,8$ bonding in $(-)-16 / 17$ leading to photoproducts with interchanged methyl patterns as well as 1,3-acyl shifts are observed but remain unimportant.

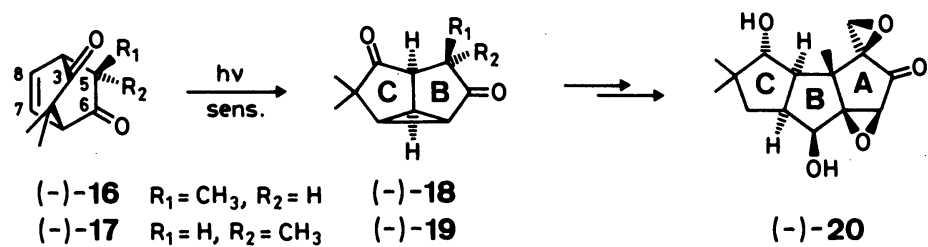

A last entry in this series concerns the use of generation (IV) building blocks. A mechanistic variant of the ODPM rearrangement includes two consecutive single-step photoreactions, $21 \rightarrow 22 \rightarrow 23$, providing access to a potential progenitor (24) of pentalenolactone $G$ (25) in $58 \%$ overall yield from 21 (acetone solution with $20 \%$ acetophenone added, $\lambda(i \mathrm{rr}) \geq 340 \mathrm{~nm}$, see ref. 18). It should be noted that the primary photoproduct 22 is a transient formed in low steady-state concentration ( $\max .5 \%$ ) en route to 23 . Cyclization of the isolable photoproduct 23 to 24 was readily effected on silica gel.

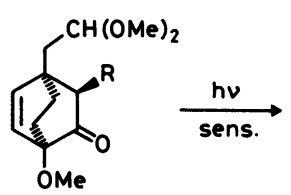

21
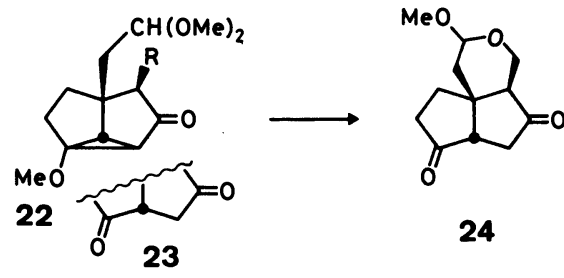

24

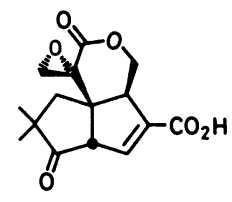

25 
Although the present scheme allows one to obtain 24 in seven steps, the further selective functionalizations required by the target stimulated the search for methods which combine simplicity with a more direct approach to provide for the functional groups in 25 (see section $B$ ).

\section{B. [2+2] PHOTOCYCLOADDITIONS OF 2-TRIMETHYLSILOXYBUTADIENE TO 2-CYCLO ALKENONES - AN ENTRY TO PENTAANNULATION}

Defining the synthetic goal. - one very direct way of constructing five-membered cycles is based on [3+2] cycloaddition methodology (part of ref. $3)$, which includes a number of interesting solutions ranging from, e.g., metal-catalyzed (ref. 19) to photochemical processes (ref. 20). The latter work exclusively concerns the preparation of heterocycles. Our own intention focused on devising a handy access to five-membered carbacycles with a high degree of stereo- and regiocontrol, starting from readily available reactants (ref. 21). Such objectives, not always satisfactorily achieved by known methods, were now sought to be accomplished by a two-step sequence mimicking the overall [3+2] process depicted in Fig. 2.

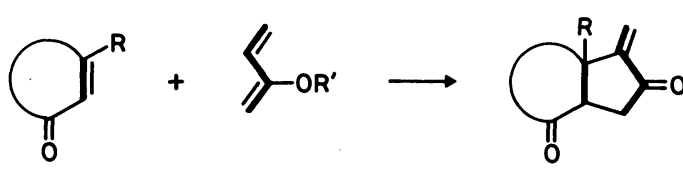

Fig. 2. Synthetic task: pentaannulation using 2-cycloalkenones and 2-trimethylsiloxybutadiene.

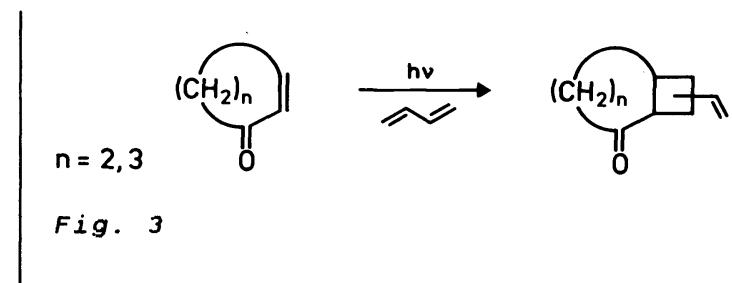

The two-step sequence consists of consecutively adding a diene component to 2-cycloalkenones in a [2+2] photoprocess and subjecting the adducts to a one-carbon ring expansion. The most dominant question concerned the choice of an adequate diene which would efficaciously serve our need. With respect to the common use of 1,3-dienes for triplet quenching, Cantrell cautioned against the use of 1,3-butadiene as a quencher of enone triplets, since it competitively reacts with the enones to form cyclobutanes (Fig. 3, ref. 22; for further photochemical reactions of dienes, see ref. 23). Nearly random regioand stereolsomeric product distributions result from these additions which occasionally proceed in high chemical yields.

If a handle for the selectivity control of such processes could be found, they would constitute a powerful synthetic method since the photoproducts could serve as substrates for various ring transformations, e.g., the enlargement of the cyclobutane. Tsuda found that 2-trimethylsiloxybutadiene adds readily and selectively to a particular heterocyclic class of enone-reminescent substrates possessing extended chromophores (ref. 24). Our investigations revealed a more general utility of this siloxy-substituted diene. It reacts smoothly with a high level of regio- and stereocontrol, with various five- and six-membered 2-cycloalkenones (refs. $21,25,26$ ), some selected examples of which are listed in Table 1.

The enhanced selectivity observed for 2-trimethylsiloxybutadiene as compared to 1,3-butadiene parallels somewhat the well-established olefin + enone photochemistry where alkoxy substitution of the olefin components is important for the selective steering of the additions (ref. 27).

Both the substituents at the enone $\beta$-carbon and the ring size of the enone influence markedly the stereocontrol of the addition processes. Furthermore, it should be noted that the conversion rates are higher upon irradiation at $350 \mathrm{~nm}$ than at $300 \mathrm{~nm}$. The greater efficiency of these [2+2] additions at longer wavelength is possibly a consequence of initial ground state complexation of the reactants, which is manifested by a charge transfer absorption at ca. $340 \mathrm{~nm}$.

A first synthetic application in this series was accomplished with the stereoisomeric mixture of photoproducts of run (2) in Table 1. Via a Pd-mediated vinyl cyclobutanol-type rearrangement, for which a known procedure (ref. 28) was adopted, 26 could be synthesized in three high-yield steps. Evidently, the structural features of 26 are more closely fitting the target, pentalenolactone $G(25)$, than do the features of the previously prepared 24 (see

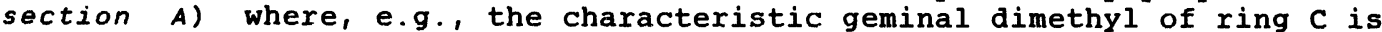
lacking. 
Table 1 :

\begin{tabular}{ccccc}
\hline Run & Dnone & Diene & Ratio of \\
(a) & (a) & products & $\begin{array}{c}\text { Yield } \\
\text { (b) } \\
\text { istereo- } \\
\text { isomers* } \\
\text { (b) }\end{array}$ \\
\hline
\end{tabular}

(1)<smiles>[R]OC(=C)C=C</smiles>

\section{9}

$19: 1$

(2)<smiles>CCOC(=O)CC1=CC(=O)C(C)(C)C1</smiles>

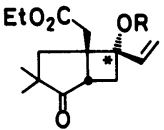

65

$12: 1$

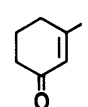

川

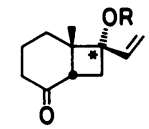

Table 2 :

Run Dioxen- Olefin Photopro- Yield one (a) (a) duct $(s)(b)(z)(c)$

$(-)-27$

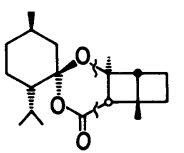

$43(d)$

$$
(-)-27
$$<smiles>[Y]C1CC([Y])C2CC1C2</smiles>

$(-)-27$<smiles>C1=CCCCC1</smiles>

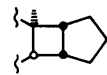

$9: 1$

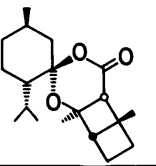

44

(a) Enone:diene molar ratio 1:5 in dimethoxyethane at $5{ }^{\circ} \mathrm{C}$. (b) Yields refer to the mixture of stereoisomers and are based on the percentage of consumed enone; average conversions $80-90 \%$. (c) Major stereoisomer as depicted.

\section{OPTICALLY PURE CYCLIC 1,3-DIOXENONES AS SUBSTRATES FOR ASYMMETRIC PHOTOCYCLOADDITIONS}

The study of asymmetric inductions in [2+2] photocycloadditions of enones or enone-type chromophores with olefins has been the theme of numerous investigations, both in the inter- and intramolecular versions (ref. 27). A most recent report (ref. 29), paralleling our own work in this field, concerns a novel aspect of the parent methodology in that a chiral auxiliary attached to the enone component directs the cycloaddition and can finally be disconnected and recovered. Our design of the enone took into consideration its ease of preparation, the ultimate disconnection of the auxiliary under mild conditions, and most notably a novel approach to effective stereofacial differentiation by

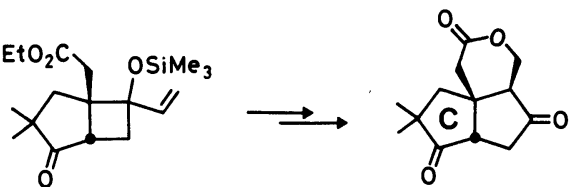

26

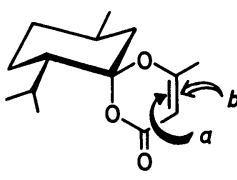

$(-)-27$

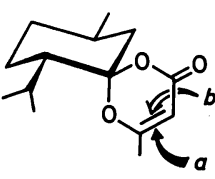

$(-)-28$

Fig. 4

a rigid spirocyclic arrangement of the auxiliary and the enone part (ref. 30). This concept was fully satisfied by the 1,3 -dioxenones $(-)-27 / 28$ (Fig. 4) which can be obtained in controllable ratios by acid-catalyzed condensation of $t$-butyl acetylacetonate with $(-)$-menthone. Spontaneous crystallization of $(-)-28$ allows a facile preparation of both enones in pure form.

The de Mayo-type photoadditions of (-)-27 were probed with a number of olefins, listed in Table 2, using a medium pressure Hg-lamp (quartz vessel). Related earlier work, which was based on the use of an achiral monocyclic 1,3-dioxenone (ref. 31), served as a background for the present studies. The regioselection varies for the addition processes from 1:3 [run (2) of the Table] to 1:7 [run (1)] and favours consistently the head-to-head adducts shown. The stereofacial differentiation is uniformly high [runs (1)-(3)] and amounts to at least an 8-fold preference for site a over site $b$ addition (cf. Fig. 4) of the olefins to (-)-27. Conformational effects seem to be more important for the faceselective steering of the addition processes than, e.g., shielding of the enone a-site by the isopropyl group. The yields reported were obtained under preliminary experimental conditions which are not yet fully optimized and they refer in each case to the major isomer after purification. 
The value of this methodology is best documented by a first synthetic application, the elaboration of $(+)$-grandisol (29) in three steps from the main photoproduct of run (1). This synthesis, employing a total of five steps, constitutes the hitherto shortest access to the boll weevil

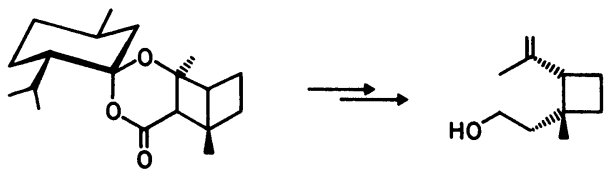
pheromone (refs. 30,32 ).

The cycloaddition of methyl cyclobutene to (-)-28 [run (4)] proceeded with a face- and regioselectivity which was practically identical to that of run (1). This finding is particularly attractive in that the preferential site a addition of olefins to both dioxenones, $(-)-27$ and $(-)-28$, can serve to select complementary enantiomeric channels.

\section{Acknowledgements}

These results were made possible by the enthusiastic collaboration of many postdoctoral research associates, graduate students and technical assistants whose names appear as coauthors in the references. Support for fellowships by the Alexander-von-Humboldt Foundation (to Drs B. Pandey and P. Dalmases) and the Deutsche Forschungsgemeinschaft are gratefully acknowledged.

\section{REFERENCES}

1. B.M. Trost, Chem. Soc. Rev. 11, 141 (1982).

2. For a comprehensive review on polyquinane chemistry, see L.A. Paquette, rop. Curr. Chem. 119, 1 (1984)

3. For a review on pentaannulation, see M. Ramaiah, synthesis, 529 (1984).

4. M. Demuth and K. Schaffner, Angew. Chem. 94, 809 (1982); Angew. Chem. Int. Ed. Engl. 21, 820 (1982)

5. M. Demuth, Chimia 38, 257 (1984).

6. K. Schaffner and M. Demuth, in Modern Synthetic Methods 4, ed. R. Scheffold, Springer-Verlag, p. 61 (1986)

7. M. Demuth, in Modern Synthetic Methods 4, ed. R. Scheffold, Springer-Verlag, p. 89 (1986).

8. P. Ritterskamp, M. Demuth and K. Schaffner, J. Org. Chem. 49, 1155 (1984)

9. M. Demuth, S. Chandrasekhar and K. Schaffner, J. Am. Chem. Soc. 106, $1092(1984)$

10. M. Demuth, A. Canovas, E. Weigt, C. Krüger and Y. H. Tsay, Angew. Chem. 95, 747 (1983); Angew. Chem. Int. Ed. Engl. 22, 721 (1983); Angew. Chem. Suppl., 1053 (1983).

11. M. Demuth and G. Mikhail, Helv. Chim. Acta 66, 2362 (1983).

12. M. Demuth, T. Planas and G. Mikhail, unpublished results.

13. M. Demuth and $W$. Hinsken, Angew. Chem. 97, 974 (1985); Angew. Chem. Int. Ed. Engl. 24, 973 (1985).

14. W. Hinsken and $M$. Demuth, J. Am. Chem. Soc. 108, in press (1986).

15. L.A. Paquette, R.A. Roberts and G.J. Drtina, J. Am. Chem. SoC. 106, 6690 (1984)

16. P.A. Wender and S.K. Singh, Tetrahedron Lett. 26,5987 (1985). D.P. Curran and S.-C. Kuo, J. Am. Chem. Soc. 108, 1106 (1986).

17. M. Demuth, P. Ritterskamp, E. Weigt and K. Schaffner, J. Am. Chem. Soc. 108 , in press $(1986)$

18. M. Demuth, B. Wietfeld, B. Pandey and K. Schaffner, Angew. Chem. 97, 777 (1985); Angew. Chem. Int. Ed. Engl. 24, 763 (1985).

19. B.M. Trost, Angew. Chem. 98, 1 (1986); Angew. Chem. Int. Ed. Engl. 25, 1 (1986). P. Binger and H.M. Büch, Top. Curr. Chem. 135, in press.

20. a) M. Nastasi and $J$. Streith, in Rearrangements in Ground and Excited states, vol. 3, ed. P. de Mayo, Academic Press, New York, p. 445 (1980). b) A. Padwa, Ibid., vol. 3, p. 501 (1980).

21. M. Demuth, B. Pandey and A. Nieto-Galan, J. Am. Chem. Soc. 108, in press $(1986)$.

22. T.S. Cantrell, Tetrahedron Lett., 3027 (1972); J. org. Chem. 39,3063 (1974).

23. G. Kaupp, in Houben-Weyl Methoden der organischen Chemie IV-5a, Georg Thieme, Stuttgart, pp. 280, 360 (1975).

24. T. Sano, J. Toda, $Y$. Horiguchi, $\mathrm{K}$. Imafuku and $\mathrm{Y}$. Tsuda, Heterocycles 16 , 1463 (1981); T. Sano, J. Toda and Y. Tsuda, Chem. Pharm. Bull. 31, 2960 (1983).

25. B. Pandey and M. Demuth, Abstr. X IUPAC Symp. Photochem., 163 (1984).

26. M. Demuth, H. Said and B. Wietfeld, manuscript in preparation.

27. For a survey on photochemical [2+2] cycloadditions, see A.C. Weedon, in Synthetic organic Photochemistry, ed. W.M. Horspool, Plenum Press, New York, p. 61 (1984).

28. G.R. Clark and S. Thiensathit, Tetrahedron Lett. 26,2503 (1985).

29. A.I. Meyers and S.A. Fleming, J. Am. Chem. Soc. $108,306(1986)$.

30. M. Demuth, A. Palomer, H. D. Sluma and A.K. Dey, manuscript in preparation.

31. S.W. Baldwin and J.M. Wilkinson, J. Am. Chem. Soc. 102, 3634 (1980)

32. For the mention of a related racemic synthesis using an achiral dioxenone, see S.W. Baldwin in organic photochemistry, vol. 5, ed. A. Padwa, Dekker, New York, p. 200 (1981). 